\title{
REDESAIN MATA PISAU PENCACAH UNTUK ALAT PEMBUAT PUPUK KOMPOS SAMPAH ORGANIK RUMAH TANGGA
}

\author{
Evi Sunarti Antu( ${ }^{1)}$, Yunita Djamalu' ${ }^{2)}$ \\ ${ }^{1,2}$ Program Studi Mesin dan Peralatan Pertanian, Politeknik Gorontalo \\ Email: evian@poligon.ac.id ${ }^{1)}$
}

\begin{abstract}
ABSTRAK
Permasalahan alat pengompos SORT (Sampah Organik Rumah Tangga) terdapat pada sistem mata pisau untuk proses pencacahan sampah. Hasil cacahan dihasilkan belum halus sehingga proses penguraiannya terhadap tanah relatif lebih lama. Selain optimalisasi pisau pencacah sampah organik, pada penelitian ini juga dilakukan pengemasan produk serta uji kemanfaatan kompos yang dihasilkan terhadap tanaman pekarangan rumah. Proses optimalisasi alat dilakukan dengan cara membuat redesain pisau pecacah. Metode yang digunakan dalam penelitian ini yakni metode kuantitatif. Dari hasil pengujian didapatkan lama waktu pencacahan adalah 33,3 detik, ukuran hasil cacahan berkisar antara 0,2-1 cm dengan menggunakan sampel 1200gr. Hasil pupuk kompos terbaik didiperoleh pada sampel dengan perlakuan limbah melalui pencacahan dan diberi larutan EM4. Pada sampel ini sudah mulai tumbuh kecambah pada hari ke lima dengan tinggi kecambah adalah $1,5 \mathrm{~cm}$. Sampel terbaik dikemas dalam satu kemasan dengan berat $5 \mathrm{~kg}$ per sak kemasan dengan tujuan untuk memberikan nilai jual yang lebih baik.
\end{abstract}

Kata Kunci: optimalisasi, pisau pencacah, pupuk kompos, sampah, pengemasan

\section{ABSTRACT}

The problem of SORT (Sampah Organik Rumah Tangga) composting tool is in the blade system for the waste enumeration process. The results of chopped are not yet smooth so the process of decomposition of the soil is relatively longer. This research will focus on optimizing the knife for chopping organic waste. Besides, product packaging and testing of the efficacy of compost produced on home garden plants will also be carried out. The process of optimizing the tool is done by making a red knife breaker design. The methode used in this reseach is the quantitative method. From the test results it was obtained that the length of the enumeration was 33.3 seconds, the size of the chopped result ranged from 0.2-1 cm using a 1200gr sample. The best compost yield was obtained in samples treated with waste through enumeration and given an EM4 solution. In this sample the germination had begun to grow on the fifth day with a sprout height of $1.5 \mathrm{~cm}$. The best sample is packaged in one package weighing $5 \mathrm{~kg}$ per sack to provide a better sale value.

\section{Keywords: optimization, chopper knife, compost fertilizer, garbage, packaging}

\section{PENDAHULUAN}

\subsection{Latar Belakang}

Kompos sangat berpotensi untuk dikembangkan mengingat semakin tingginya jumlah sampah organik yang dibuang ke tempat pembuangan akhir dan menyebabkan terjadinya polusi bau dan lepasnya gas metana ke udara. Secara alami bahan-bahan organik akan mengalami penguraian di alam dengan bantuan mikroba maupun biota tanah lainnya. Namun proses pengomposan yang terjadi secara alami berlangsung lama dan lambat. Untuk mempercepat proses pengomposan ini telah banyak dikembangkan teknologi-teknologi pengomposan. Baik pengomposan dengan teknologi sederhana, sedang, maupun teknologi tinggi.

Salah satu cara pengomposan yang sedang dikembangkan saat ini adalah pengomposan dengan sistem keranjang tatakura. Pengomposan dengan sistem ini bertujuan untuk mempermudah masyarakat dalam pengolahan sampah organiknya sendiri. Adapun desain keranjang tatakura yang sudah pernah ada masih dengan sistem manual. Pisau pencacah diputar secara manual dengan menggunakan tuas yang terhubung dengan poros mata pisau.

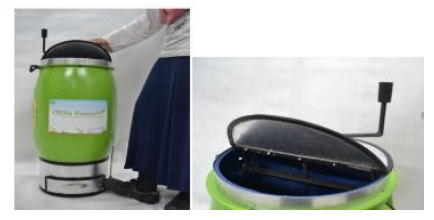

Gambar 1. Pengomposan kerajang tatakura sistem manual (Cintawati, 2013)

Berdasarkan hal tersebut maka pada penelitian sebelumnya (Antu, 2018) telah dirancang mesin pencacah pupuk kompos sampah rumah tangga dengan mengadopsi sistem keranjang tatakura. Hal ini dimaksudkan untuk mempermudah 
masyarakat dalam penggunaanya dalam pengolahan sampah organik. Namun kekurangan pada alat sebelumnya adalah hasil pencacahan yang masih belum optimal. Ukuran sampah hasil cacah masih berkisar antara $2-5 \mathrm{~cm}$, sehingga proses penguraiannya dengan tanah membutuhkan waktu yang cukup lama.

Pada penelitian ini, mata pisau pencacah didesain ulang dengan mengganti bahan mata pisau, menambah jumlah mata pisau dan menggati saringan bawah keranjang pencacah dengan tujuan untuk mendapatkan hasil cacahan yang lebih halus. Kemudian hasil penelitian diuji cobakan pada tanaman pekarangan rumah.

Kompos adalah hasil penguraian parsial/tidak lengkap dari campuran bahan-bahan organik yang dapat dipercepat secara artifisial oleh populasi berbagai macam mikroba dalam kondisi lingkungan yang hangat, lembap, dan aerobik atau anaerobik (Crawford, 2003). Sedangkan pengomposan adalah proses di mana bahan organik mengalami penguraian secara biologis, khususnya oleh mikroba-mikroba yang memanfaatkan bahan organik sebagai sumber energi. Membuat kompos adalah mengatur dan mengontrol proses alami tersebut agar kompos dapat terbentuk lebih cepat. Proses ini meliputi membuat campuran bahan yang seimbang, pemberian air yang cukup, pengaturan aerasi, dan penambahan aktivator pengomposan.

Pengertian EM4 menurut Kartika (Kartika, 2013) adalah pupuk berbentuk cairan yang terdiri atas suatu kultur campuran berbagai mikroorganisme bermanfaat dan menyuburkan tanah. Manfaat EM4 menurut Indriani (Indriani, 2011) dalam proses fermentasi bahan organik, mikroorganisme akan bekerja dengan baik bila kondisi sesuai. Proses fermentasi akan berlangsung dalam kondisi anaerob, $\mathrm{pH}$ rendah (3-4), kadar garam dan gula tinggi, kandungan air sedang 30$40 \%$, kandungan antioksidan dari tanaman rempah dan obat, adanya mikroorganisme fermentasi, serta suhu yang mendukung (40-50\% oC).

\subsection{Justifikasi Permasalahan}

1. Masalah alat pencacah sampah organic dan non organic yakni belum optimalnya kinerja alat pengompos SORT sehingga perlu adanya rancang ulang pisau pencacah dan alat pengaduk kompos.

2. Belum menghasilkan pupuk kompos yang dapat dimanfaatkan dan didistribusikan kepada masyarakat sebagai alternatif untuk pengolahan lahan pertanian ataupun perkebunan masyarakat.

3. Produk kompos yang belum dikemas sehingga belum dapat didistribusikan kepada masyarakat

\subsection{Tujuan Penelitian}

Tujuan dari penelitian ini adalah optimalisasi kinerja alat pembuat pupuk kompos sampah organik rumah tangga dengan melakukan desain ulang pisau pencacah.

\section{METODE PENELITIAN}

\subsection{Lokasi dan Waktu penelitian}

Pembuatan alat pengomposan dilakukan di Laboratorium Umum Mesin dan Peralatan Pertanian Politeknik Gorontalo. penelitian dilakakukan di Lab Mesin Umum pada bulan Agustus-November 2019.

\subsection{Deskripsi Alat}

Proses desain dilakukan dengan cara membuat desain pisau pecacah, sistem pengaduk dan proses penyaringan, Desain yang dipilih dari literatur yang ada adalah desain dengan sistem paling sederhana yang mudah dibuat, murah dan praktis saat dioperasikan. Alternatif desain terpilih dibuat dari bahan alumunium sebagai tempat bioreaktor pengomposan yang dilubangi di bawahnya dan ditambahkan lempengan alumunium sebagai alasnya yang berfungsi menampung kompos jadi hasil saringan yang diletakkan di antara dasar tong dengan tabung alumunium, sedangkan tong alumunium dibuat dengan diameter $40 \mathrm{~cm}$ dan tinggi $40 \mathrm{~cm}$ dengan dudukan ataupun penampung berupa laci sebagai wadah menampung hasil olahan pupuk kompos dengan tinggi keseluruhan mencapai $40 \mathrm{~cm}$. Pencacah dan pengaduk dibuat sekaligus dengan pisau berbentuk sabit dan digerakan otomatis melalui dinamo dengan sistem penghantar putaran yang sederhana.

Sistem dari alat pengomposan sampah organik dibagi menjadi enam bagian utama yaitu perancangan bagian hoper inlet, perancangan tong alumunium sebagai wadah pengaduk sampah, perancangan mekanik system penggerak menggunakan dinamo listrik, perancangan laci penampung hasil pengomposan, penyaring dari bahan alumunium dan desain alat pencacah sekaligus pengaduk sampah.

\subsection{Teknik Pengumpulan Data}

Teknik pengumpulan data dilakukan dengan 2 cara yaitu :

1. Teknik Uji Kinerja

Dilakukan dengan uji coba kinerja alat pengomposan sampah dengan sistem penggerak menggunakan dinamo.

2. Teknik Analisis Data

Dilakukan dengan menganalisa data yang diambil saat uji kinerja alat.

\section{HASIL DAN PEMBAHASAN}

\subsection{Optimalisasi kinerja alat dengan redesain mata pisau}

Pada desain alat pada penelitian sebelumnya (Antu, 2018), alat pengomposan dirancang dengan 4 
laci pengomposan dengan masing-masing rak/laci mempunyai volume $0,032 \mathrm{~m}^{3}$. Hal ini dirancang agar dapat menampung sampah organik rumah tangga 1-2 hari. Laci penyimpanan pupuk kompos dirancang dengan menggunakan bahan stainless still dengan tujuan agar terhindar dari korosi (berkarat) saat pengomposan.

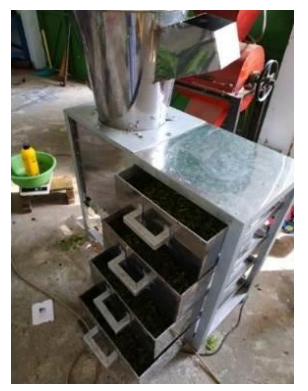

Gambar 2. Alat Pengomposan sampah organik rumah tangga

Dari Gambar 2 dapat dilihat bahwa alat pengomposan ini didesain mempunyai 4 rak/laci pengomposan dengan desain yang akan memudahkan ibu-ibu rumah tangga dalam pembuatan dan penyimpanan pupuk kompos dengan memanfaatkan limbah dapur berupa sisa bahan makanan organik, sisa olahan sayuran, sisa buahbuahan dan sejenisnya.

Mata pisau pencacah dirancang dengan lebih kuat dan tajam dengan tujuan hasil cacahan lebih halus dan membutuhkan waktu yang lebih singkat dalam pencacahan.

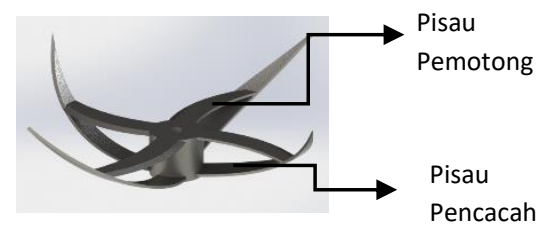

Gambar 3. Desain Mata Pisau

Mata pisau pada penelitian sebelumnya menggunakan mata pisau sabit yang dimodifikasi menjadi mata pisau pencacah. Dari mata pisau tersebut dihasilkan hasil cacahan yang masih kasar dan mata pisau tersebut cepat tumpul dan tidak kuat mencacah batang yang agak keras. Sehingga mata pisau didesain kemabali dengan mnggunakan bahan besi dengan susunan struktur mata pisau seperti pada gambar 3. Stuktur mata pisau bagian atas digunakan untuk memotong limbah menjadi bagian kecil-kecil sehingga lebih mudah dicacah halus pada struktur mata pisau bagian bawah. Bentuk mata pisau ini mengadopsi model mata pisau blender (penghancur makanan) dengan kemiringan $15^{\circ}$. Hasil cacahan dan waktu yang dibutuhkan mata pisau pencacah dapat dilihat dari Tabel 1 :
Tabel 1. Hasil Pencacahan Limbah Sayur

\begin{tabular}{clccc}
\hline $\begin{array}{c}\text { Uji } \\
\text { coba } \\
\text { ke- }\end{array}$ & $\begin{array}{c}\text { Jenis } \\
\text { Sampah }\end{array}$ & $\begin{array}{c}\text { Berat } \\
\text { Sampah }\end{array}$ & $\begin{array}{c}\text { Rata-rata } \\
\text { Waktu } \\
\text { Pencaahan }\end{array}$ & $\begin{array}{c}\text { Ukuran } \\
\text { Hasil } \\
\text { Cacahan }\end{array}$ \\
\hline I & $\begin{array}{l}\text { Sisa } \\
\text { Sayuran }\end{array}$ & $1200 \mathrm{gr}$ & 33 detik & $0.2-1 \mathrm{~cm}$ \\
II & $\begin{array}{l}\text { Sisa } \\
\text { Sayuran }\end{array}$ & $1200 \mathrm{gr}$ & 35 detik & $0.2-1 \mathrm{~cm}$ \\
III & $\begin{array}{l}\text { Sisa } \\
\text { Sayuran }\end{array}$ & $1200 \mathrm{gr}$ & 32 detik & $0.2-1 \mathrm{~cm}$ \\
& & & \\
\hline \multicolumn{7}{l}{ Rata-rata } & $\mathbf{3 3 , 3}$ detik & $\mathbf{0 . 2}-\mathbf{1 ~ c m}$ \\
\hline
\end{tabular}

Dari Tabel 1 dapat dilihat bahwa rata-rata waktu pencacahan adalah 33,3 detik dengan ukuran hasil cacahan adalah berkisar dari $0,2-1 \mathrm{~cm}$ menggunakan berat sampel $1200 \mathrm{~g}$ limbah sayur. Dengan mengubah bentuk mata pisau maka ukuran hasil cacahan semakin kecil sehingga akan cepat bercampur dan terurai dengan tanah.



(a)

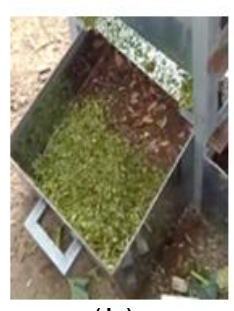

(b)
Gambar 4. Hasil cacahan pada penelitian sebelumnya (a) dan hasil cacahan setelah redesain mata pisau (b)

Dari Gambar 4 dapat dilihat perbedaan hasil cacahan pada penelitian sebelumnya (a) dan hasil cacahan setelah me redesain mata pisau (b). Pada gambar (a) hasil cacahan masih terlihat kasar. Ukuran hasil cacahan berkisar antara $1,5-2 \mathrm{~cm}$. Sedangkan pada gambar (b) hasil cacahan terlihat sangat halus dibandingkan dengan hasil cacahan pada gambar (a). ukuran hasil cacahan rata-rata berkisar dari $0,2-1 \mathrm{~cm}$

\subsection{Proses Pengomposan}

Limbah sisa makanan dan sisa potongan sayuran dikumpulkan menjadi satu dalam satu wadah kemudian ditimbang untuk mengetahui berat sampel. Kemudian limbah tersebut dimasukkan kedalam mesin pencacah. Hal ini dimaksudkan agar limbah cepat terurai. Setelah melalui proses pencacahan, selanjutnya limbah tersebut dicampur dengan sedikit tanah dan kemudian dicampurkan dengan cairan EM4 yang telah ditambahkan air dan gula pasir. Pengadukan dilakukan setiap 2 hari sekali agar limbah dan tanah tercampur dengan baik. Pada percobaan penelitian ini diberikan perlakuan yang berbeda dari masing-masing rak/laci.

a. Laci Nomor 1 
Limbah Sisa Sayuran tanpa melalui proses pencacahan dicampur dengan tanah dan tanpa diberi larutan EM4.

b. Laci Nomor 2

Limbah Sisa Sayuran melalui proses pencacahan dicampur dengan tanah dan tanpa diberi larutan EM4

c. Laci Nomor 3

Limbah Sisa Sayuran melalui proses pencacahan dicampur dengan tanah dan diberi larutan EM4

d. Laci Nomor 4

Limbah Sisa Sayuran tanpa melalui proses pencacahan dicampur dengan tanah dan diberi larutan EM4

Dari hasil pengujian dengan empat perlakuan berbeda tersebut maka didapatkan hasil pengujian sebagai berikut :

Tabel 2. Data Hasil Pengujian Rak 1

\begin{tabular}{cll}
\hline $\begin{array}{c}\text { Hari } \\
\text { Ke- }\end{array}$ & \multicolumn{1}{c}{ Parameter } & \multicolumn{1}{c}{ Hasil Pengujian } \\
\hline I & Bau & Berbau Tanah \\
& Warna & Coklat \\
& Pertumbuhan & Belum ada \\
III & Bau & Berbau Tanah \\
& Warna & Coklat Pudar \\
& Pertumbuhan & Belum ada \\
V & Kecambah & Berbau Tanah \\
& Warna & Coklat pudar (tanah \\
& & dan limbah \\
& Pertumbuhan & mengering) \\
& Kecambah & Belum ada \\
VII & Bau & Berbau Tanah \\
& Warna & Coklat pudar (tanah \\
& & dan limbah semakin \\
& & mengering) \\
& Pertumbuhan & Belum ada
\end{tabular}

Dari Tabel 2 dapat dilihat bahwa perubahan bau dan warna tanah hingga hari ke tujuh tidak terlalu terlihat perubahannya. Proses pengomposan pada laci 1 merupakan proses pengomposan alami tanpa melalui pencacahan dan penggunaan EM4. Sehingga penguraian limbah organik dengan tanah akan membutuhkan waktu yang lama.
Tabel 3. Data Hasil Pengujian Rak 2

\begin{tabular}{|c|c|c|}
\hline $\begin{array}{c}\text { Hari } \\
\text { Ke- }\end{array}$ & Parameter & Hasil Pengujian \\
\hline \multirow[t]{3}{*}{ I } & Bau & Berbau Tanah \\
\hline & Warna & Coklat \\
\hline & Pertumbuhan & Belum ada \\
\hline \multirow[t]{3}{*}{ III } & $\mathrm{Bau}$ & Berbau Tanah \\
\hline & Warna & Coklat \\
\hline & $\begin{array}{l}\text { Pertumbuhan } \\
\text { Kecambah }\end{array}$ & Belum ada \\
\hline \multirow[t]{3}{*}{ V } & $\mathrm{Bau}$ & Berbau Busuk \\
\hline & Warna & Coklat \\
\hline & $\begin{array}{l}\text { Pertumbuhan } \\
\text { Kecambah }\end{array}$ & Belum ada \\
\hline \multirow[t]{3}{*}{ VII } & $\mathrm{Bau}$ & Berbau Busuk \\
\hline & Warna & Coklat \\
\hline & $\begin{array}{l}\text { Pertumbuhan } \\
\text { Kecambah }\end{array}$ & Belum ada \\
\hline
\end{tabular}

Dari Tabel 3 dapat dengan perlakuan melalui pencacahan tanpa ditambahkan EM4 dapat dilihat bahwa warna tanah tidak berubah dan tidak cepat mengering seperti pada pengujian Tabel 2. Hal ini dikarenakan limbah melalui pencacahan terlebih dahulu sehingga penguraian limbah dengan tanah sangat cepat dibandingkan dengan pengujian pada rak 1 .

Tabel 4. Data Hasil Pengujian Rak 3

\begin{tabular}{cll}
\hline $\begin{array}{c}\text { Hari } \\
\text { Ke- }\end{array}$ & \multicolumn{1}{c}{ Parameter } & \multicolumn{1}{c}{ Hasil Pengujian } \\
\hline I & Bau & Berbau Tanah \\
& Warna & Coklat \\
& Pertumbuhan & Belum ada \\
III & Bau & Berbau Tanah \\
& Warna & Coklat \\
& Pertumbuhan & Belum ada \\
& Kecambah & \\
V & Bau & Berbau Busuk \\
& & (semakin tajam) \\
& Warna & Coklat Kehitaman \\
& Pertumbuhan & 0,75 cm \\
KII & Kecambah & \\
& Bau & Berbau Busuk \\
& Warna & Coklat Kehitaman \\
& Pertumbuhan & $1,5 \mathrm{~cm}$ \\
& Kecambah & \\
\hline
\end{tabular}

Pada Tabel 4 di atas dengan pengujian melalui proses pencacahan dan penambahan EM4 dapat dilihat bahwa warna tanah mengalami perubahan dan bau yang ditimbulkan juga mengalami perubahan menjadi sangat busuk. Hal ini 
pengaruh ditambahkan EM4. Pada Tabel 4 ini juga terlihat sudah mulai ada kecambah yang tumbuh pada hari ke lima.

Tabel 5. Data Hasil Pengujian Rak 4

\begin{tabular}{cll}
\hline $\begin{array}{c}\text { Hari } \\
\text { Ke- }\end{array}$ & \multicolumn{1}{c}{ Parameter } & \multicolumn{1}{c}{ Hasil Pengujian } \\
\hline I & Bau & Berbau Tanah \\
& Warna & Coklat \\
& Pertumbuhan & Belum ada \\
III & Bau & Berbau Tanah \\
& Warna & Coklat \\
& Pertumbuhan & Belum ada \\
Vecambah & Bau & Berbau Busuk \\
& & (semakin tajam) \\
& Warna & Coklat Kehitaman \\
& Pertumbuhan & Belum ada \\
& Kecambah & \\
VII & Bau & Berbau Busuk \\
& & (semakin tajam) \\
& Warna & Coklat Kehitaman \\
& Pertumbuhan & Belum ada \\
& Kecambah & \\
\hline
\end{tabular}

Dari data Tabel 5 menunjukan bahwa perubahan yang terlihat ada pada bau dan warna tanah. Bau semakin menusuk dan warna tanah semakin kehitaman. Sedangkan pertumbuhan kecambah hingga hari ketujuh belum ada. Pada laci kelima ini dilakukan pengujian dengan perlakuan tanpa melalui proses pencacahan dan ditambahkan EM4.

Dari data tabel di atas dapat dilihat bahwa, hasil pengujian terbaik adalah terdapat pada Tabel 4 yakni hasil pengujian pada rak ke-3 dengan perlakuan limbah melalui proses pencacahan dan penambahan EM4. Dari tabel hasil pengujian tersebut dapat disimpulkan bahwa proses pencacahan sangat penting dilakukan karena sangat berpengaruh pada hasil dari proses pengomposan.

\subsection{Pengemasan Kompos}

Pengemasan pupuk kompos dilakukan selain terlihat lebih menarik juga agar mempunyai nilai komersial yang sesuai. Pupuk kompos yang dikemas adalah pupuk kompos pada laci/rak ke 3 dari hasil pengujian. Pupuk kompos dikemas dengan berat 5 $\mathrm{kg}$ per sak.

Hasil dari pengomposan sampah organik rumah tangga dikemas dalam kemasan plastik ukuran $5 \mathrm{~kg}$ seperti pada gambar 5 dengan tujuan agar mudah dipasarkan. Selain itu tanah dengan campuran olahan sampah organik rumah tangga ini sudah diaplikasikan pada tanaman pekarangan. Uji coba dilakukan pada tanaman hias yang ada pada pekarangan rumah masyarakat. Hasilnya tanaman hias semakin subur dan daunnya kelihatan segar.

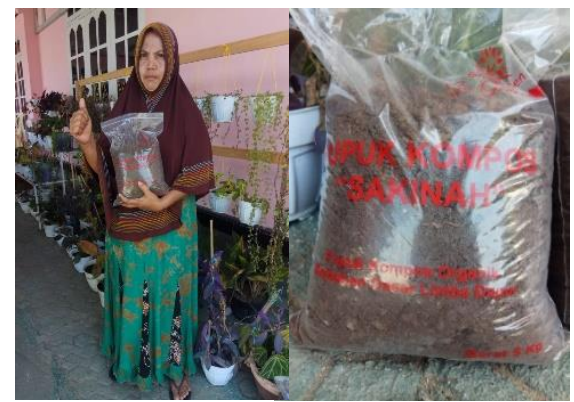

Gambar 5. Kemasan Pupuk Kompos Sampah Organik Rumah Tangga

\section{KESIMPULAN DAN SARAN}

4.1. Kesimpulan

Dari hasil penelitian dapat dismpulkan :

a. Dengan mengoptimalkan kinerja mata pisau maka hasil cacahan lebih halus dan waktu pencacahan lebih singkat. Berat sampel yang diujikan yakni 1200 gr. Ukuran hasil cacahan berkisar 0,2-1 cm dengan waktu 33,3 detik.

b. Dari hasil uji coba didapatkan bahwa hasil terbaik pada pengujian adalah pada rak/laci ke tiga dengan perlakuan sampel melalui pencacahan dan dengan menambahkan laruatan EM4 pada sampel.

\subsection{Saran}

Dari hasil penelitian ini peneliti menemukan hal yang bisa dijadikan saran untuk penelitian berikutnya yakni pada bagian masing-masing rak/laci dari penyimpanan pupuk dibuatkan alat pengaduk yang bisa mengaduk sampel pupuk dengan mudah.

\section{DAFTAR PUSTAKA}

Antu, S. E. D. Y. (2018). Desain Mesin Pencacah Sampah Organik Rumah Tangga Untuk Pembuatan Pupuk Kompos. JTPG, 3(Nomor 2), 57-65.

Cintawati, R. N. dkk. (2013). Desain Alat Pengompos sampah Rumah Tangga pengembangan alnjut dari keranjang tatakura. Jurnal Tingkat Sarjana Seni Rupa Dan Desain, No 1.

Crawford, J. (2003). KOMPOS. In Balai Penelitian Bioteknologi Perkebunan Indonesia.

Indriani, H. Y. (2011). Pembuatan Pupuk Kilat. Jakarta: Penebar Swadaya.

Kartika, G. J. (2013). Bertanam dan Sayuran Organik. Jakarta: Penebar Swadaya. 